\title{
Food Safety Knowledge, Attitude and Self-Reported Practices among Medical Students at Ain Shams University, Egypt
}

\author{
Dina N.K. Boulos and Nahla Fawzy Abouelezz
}

Department of Community, Environmental and Occupational Medicine, Faculty of Medicine, Ain Shams University, Cairo, Egypt

\section{Abstract}

Background: Foodborne diseases are a growing public health problem. The study of food safety knowledge and practice among university students is crucial as they are usually involved in food preparation for themselves and they are also the future food handlers for other household members. Objective: To estimate the knowledge, attitude and self-reported practice of food safety among medical students and to identify the relation of food safety knowledge on attitude and practice. Method: A cross sectional study was conducted at the Faculty of Medicine, Ain Shams University using a validated, anonymous self-administrated questionnaire that included several sections; sociodemographic data, food safety knowledge, attitude and questions related to food safety practice. Results: The questionnaire was completed by 244 medical students from the six faculty grades, $47 \%$ were males and $52.9 \%$ females, mean age in years \pm SD was 21.9 \pm 1.7. An insufficient level of food safety knowledge was found among students. Correct answers for the six food safety knowledge questions were selected by less than $50 \%$ of studied students. By gender, females had significantly higher food safety knowledge, attitude and practice mean scores $(\mathrm{t}=-3.01$ $\mathrm{p}=0.003-\mathrm{t}=-2.5 \mathrm{p}=0.013-\mathrm{t}=-3.03 \mathrm{p}=0.003)$ respectively. Knowledge score correlation with attitude and practice scores showed no statistical significance $(\mathrm{r}=0.04 \mathrm{p}=0.45$ and $\mathrm{r}=0.11$ $\mathrm{p}=0.07)$ respectively. Students with more positive food safety attitude reported safer food practices $(\mathrm{r}=0.28 \mathrm{p}<0.001)$. Conclusion: The insufficient level of food safety knowledge in this study highlighted the need to develop continued education on food safety targeting university students.

Keywords: Food safety, Food borne illness, university students

Corresponding Author: Dina N. K. Boulos, , E-mail: dnkamel@med.asu.edu.eg

\section{Introduction}

Globally food borne diseases are a growing public health problem with high toll on morbidity and mortality. ${ }^{1}$ Annually, millions of people suffer from food-borne diseases and illnesses resulting from the consumption of contaminated food. ${ }^{2}$ This leads to loss of productivity, diminished quality of life as well as imposing high economic burden. ${ }^{3}$ Food safety is defined as the degree of confidence that food will not cause harm to anyone who consumes it. This occurs through handling, preparing and storing food in a way to optimally reduce the risk of individuals becoming sick from foodborne illnesses. ${ }^{3}$ Although it is problematic to accurately estimate the incidence of food-borne diseases worldwide, It has been estimated that around 2 million people die each year from diarrheal diseases, mainly due to contaminated food and water. ${ }^{4}$ Food borne outbreaks are mainly due to many factors 
as food storage (time and temperature), contaminated equipment, lack of personal hygiene, unsafe food and water sources and improper cooking. ${ }^{5}$ According to Lee et al, 2017, more than $50 \%$ of the total food poisoning cases were attributed to improper food handling. Recent studies have shown that around 50 to $87 \%$ of foodborne outbreaks occur due to wrong home practices. ${ }^{6}$ In US improper domestic food handling was responsible for 9 to $15 \%$ of cases between 1998 and $2008 .^{7-8}$ Food safety at home might affect not only the home occupants but may extend to a wider community. Currently in many countries, home kitchen may also be used for small home-based business that prepare and cater food for the community outside of the home. An important issue is that these catering activities are usually unregulated, not under supervision of any authority for kitchens and people involved may not have been trained in food safety. ${ }^{9}$ Food safety knowledge increases with age and practice. Females have higher scores than males. ${ }^{10}$ In a study assessing the level of food safety knowledge among Jordanian female students staying in dorms, around one third of the participants $(33.9 \%)$ answered correctly more than $50 \%$ of the questionnaire. $^{11}$

It is crucial to study food safety knowledge and practice among university students as they are usually involved in food preparation for themselves. In addition, they are the future food handlers for household members as children, pregnant women and elderly. Research on food safety understanding and practice in Egypt is scarce. Understanding food safety knowledge, attitude and practice is a critical step to develop a well-tailored education program. This study aims to identify the knowledge, attitude and self reported practice of food safety among medical students at Ain Shams University in Cairo, as well as to identify the relation of knowledge of food safety on attitude and practice among the studied medical students.

\section{Method}

Study design: A cross sectional study was carried out. The study was conducted from April 2017 until June 2017.The sample consisted of 195 undergraduate students enrolled from different grades of Faculty of Medicine at Ain Shams University located in Cairo, Egypt.

A sample of 195 medical students was estimated at 95\% CI, using Epi-Info 7 taking a prevalence of knowledge among youth was $53 \%{ }^{11}$ with standard deviation of $7 \%$. The questionnaire was distributed to 300 students, the completion was anonymous and voluntary. Out of this number 244 were completed and included in the analysis (response rate $81.3 \%$ ).

Study tool: Data was collected using a validated, anonymous self-administrated questionnaire. The used questionnaire was adapted from Majowicz et al.2016. ${ }^{12}$ The questionnaire included several sections: The first part included demographic data as age, gender, grade, residence and selfpreparation of meals. The second part consisted of six questions on food safety knowledge. The answers were graded by assigning one point for the correct answer and 0 point for the wrong answer. The total score of food safety knowledge for each student was calculated by summation of the correct answers. Higher scores denote higher knowledge. The third part included four questions on attitude towards food safety using a 5-Likert-scale format. The answers ranged from zero for strongly disagree to (4) for strongly agree. The fourth part included four questions related to food safety practice during food preparation. The practice questions were assigned the following scores: 'never', 1 
point, 'rarely', 2 points, 'sometimes', 3 points, 'usually', 4 points and 'always', 5 points. The questionnaire was peer reviewed and a pilot study was carried out on 10 students for wording clarity, understandability and time needed to fill it. The results of the pilot study were not included in the final analysis.

\section{Data Analysis}

Statistical analysis was performed using IBM SPSS version 22 (Statistical Package for Social Sciences) with a $\mathrm{p}$ value less than 0.05 being considered statistically significant. Quantitative data, such as age, were presented as means and standard deviations. The independent t-test was used to compare two groups. Qualitative data were presented as counts and percentages. The Chi square test was used to verify association between different categorical variables.

\section{Ethical consideration}

The protocol of the study was submitted to the Ethical Review Committee at the Faculty of Medicine, Ain Sham University prior to the study. It was an exempted research as an anonymous questionnaire was used. A verbal informed consent was obtained from each participant after the explanation of the study and assuring that participation is voluntary. The confidentiality of data was also assured.

\section{Results}

A total of 244 medical students completed the questionnaire, about $47 \%$ males and $52.9 \%$ females, mean age in years \pm SD $(21.9 \pm 1.7)$. All 6 grades were presented in the study sample. Out of the studied sample about $54 \%$ were staying with their family and the majority (95.9\%) said that they didn't work during academic year. (Table 1). Nearly one third $(31 \%)$. of the study participants cooked food or meals from basic ingredients a few times a week.
There was a statistically significant difference between males and females $\left(\mathrm{x}^{2}\right.$ $=14.7$ Table 1. Characteristics of studied medical students

\begin{tabular}{lcc}
\hline Variable & $\begin{array}{c}\text { Frequency } \\
(\mathbf{N = 2 4 4})\end{array}$ & Percent \\
\hline $\begin{array}{l}\text { Age in years } \\
\text { Mean } \pm S D\end{array}$ & \multicolumn{2}{c}{$21.9 \pm 1.7$} \\
\hline Gender & \\
Male & 115 & 47.1 \\
Female & 129 & 52.9 \\
\hline Grade & & \\
1.0 & 24 & 9.8 \\
2.0 & 21 & 8.6 \\
3.0 & 31 & 12.7 \\
4.0 & 97 & 39.8 \\
5.0 & 31 & 12.7 \\
6.0 & 40 & 16.4 \\
\hline Working & & \\
No & 234 & 95.9 \\
Yes & 10 & 4.1 \\
\hline
\end{tabular}

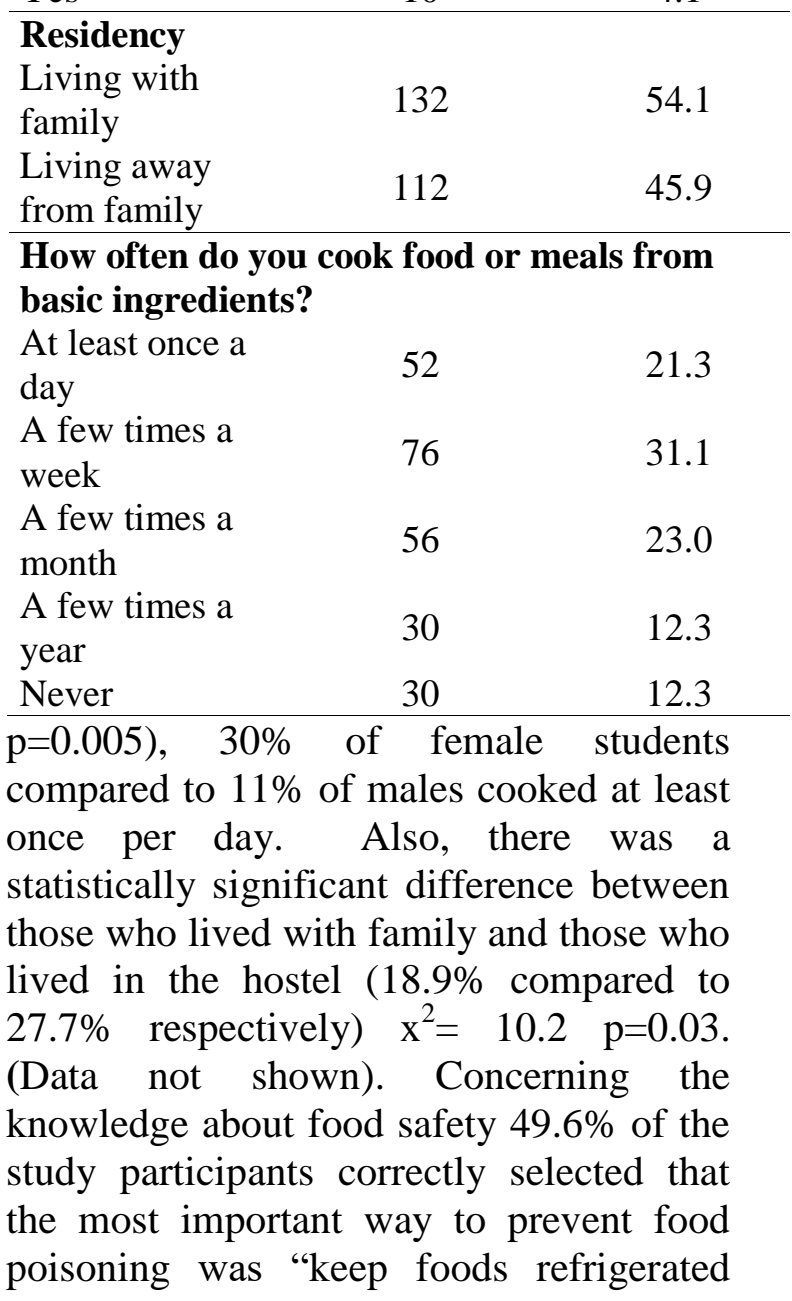

Vol. 38

No. 2 April

2020 
until it's time to cook or serve them". On

that

"leftovers

should

be

the other hand, $29.9 \%$ correctly selected

Table 2. Frequency of food safety correct knowledge among the studied medical students

\section{Knowledge}

Frequency

Percent

Which of the following is considered the most important way to prevent food poisoning?

Keep foods refrigerated until it's time to cook or serve them

121

49.6

How long should leftovers be stored in the refrigerator?

3 to 4 days

The best way to keep from getting food poisoning from fresh fruits and vegetables is to Wash them with

Cool running water 96

39.3

Which is the most hygienic way to wash your hands

Apply sanitizer, run water, rub hands together for $20 \mathrm{sec}$., rinse hands, dry hands, rub on an antiseptic hand lotion

79

32.4

If you have a sore on the back of your hand, should you prepare food for other people

Yes, if you bandage the sore and wear a glove 86 35.2

Which should not be done when storing raw meat, fish, or poultry in the refrigerator put it in the coldest place in the refrigerator

Scale passing $(\%)$

$82 \quad 33.6$

Knowledge score 50

Mean $\pm S D$

$2.2 \pm 1.3$

Table 3. Food safety attitude questions among the studied medical students

\begin{tabular}{cccc}
\hline \multirow{2}{*}{ Attitude } & Disagree & Neutral & Agree \\
& $\mathbf{N}(\%)$ & $\mathbf{N}(\%)$ & $\mathbf{N}(\%)$ \\
\hline
\end{tabular}

I like learning about how to keep my foods safe to eat

$0.0(0.0) \quad 11(4.5) \quad 233(95.5)$

I am concerned about getting food poisoning

$11(4.5)$

$61(25.0)$

$172(70.5)$

Confident about cooking safe and healthy meals

$18(7.4) \quad 52(21.3) \quad 174(71.3)$

Being able to cook safe, healthy meals is an important life skill

$12(4.9) \quad 19(7.8)$

$213(87.3)$

stored in the refrigerator 3 to 4 days". Only $39.3 \%$ reported that "the best way to prevent food poisoning from fresh fruits and vegetables was to wash them with cool running water". Nearly one third $(32.4 \%)$ selected that "the most hygienic way to wash hands is to apply sanitizer, run water, rub hands together for $20 \mathrm{sec}$., rinse hands, dry hands, rub on an antiseptic hand lotion". Concerning knowledge about what should be done if they have a sore on their hand $35 \%$ reported that they "should bandage the sore and wear a glove" females had better knowledge and the difference was statistically significant
(27.8\% among males compared to $41.9 \%$ among females) $\mathrm{x} 2=10.3 \mathrm{p}=0.036$ ). One third $(33.6 \%)$ of the study participants reported correctly that "when storing raw meat, fish, or poultry it should not be put in the coldest place in the refrigerator". Passing percentage for the six knowledge questions was 50\%, knowledge score (range 0-6) mean \pm SD were $2.2 \pm 1.3$ (Table 2). Concerning attitude towards food safety the majority $(95.5 \%)$ of studied students agreed that "they like learning about how to keep foods safe to eat". While $70.5 \%$ agreed that" they were concerned about getting food poisoning" 
and $71.3 \%$ agreed that "they were confident to cook safe, healthy meals for self and family", $7.4 \%$ disagreed. Most of the study participants $(87.3 \%)$ agreed that "being able to cook safe, healthy meals is an important life skill" (Table 3). Studied students

Table 4. Descriptive table of food safety self-reported practice questions among the studied medical students

\begin{tabular}{|c|c|c|c|}
\hline Practice & $\begin{array}{c}\text { Never/ Rarely } \\
\text { N (\%) }\end{array}$ & $\begin{array}{l}\text { Sometimes } \\
\mathbf{N}(\%)\end{array}$ & $\begin{array}{c}\text { Usually/ Always } \\
\text { N (\%) }\end{array}$ \\
\hline
\end{tabular}

I plan, or help plan, the meals in my household

$44(18.0)$

$56(23.0)$

$144(59.0)$

Before preparing or handling food, I wash my hands with soap and warm running water

$$
5(2.0) \quad 38(15.6) \quad 201(82.4)
$$

I wash my hands with soap and warm running water after working with raw meat or chicken.

$$
6(2.5) \quad 23(9.4) \quad 215(88.1)
$$

I keep raw meat and chicken away from ready-to-eat foods like raw vegetables

\begin{tabular}{llll} 
& $8(3.3)$ & $43(17.6)$ & $193(79.1)$ \\
\cline { 2 - 3 } & the & same situation. & The majority of
\end{tabular}

\begin{tabular}{|c|c|c|c|}
\hline Gender & $\mathbf{N}$ & $\begin{array}{c}\text { Mean } \\
\text { Knowledge } \\
\text { score } \pm \text { S.D. }\end{array}$ & Sig. \\
\hline Male & 115 & $1.9 \pm 1.2$ & $\mathrm{t}=-3.01$ \\
\hline Female & 129 & $2.4 \pm 1.3$ & $\mathrm{p}=0.003$ \\
\hline \multicolumn{4}{|c|}{$\begin{array}{c}\text { Mean attitude } \\
\text { score } \pm \text { SD }\end{array}$} \\
\hline Male & 115 & $6.9 \pm 1.1$ & $t=-2.5$ \\
\hline Female & 129 & $7.2 \pm 1$ & $\mathrm{p}=0.01$ \\
\hline \multicolumn{4}{|c|}{$\begin{array}{c}\text { Mean practice } \\
\text { score } \pm \text { SD }\end{array}$} \\
\hline Male & 115 & $6.6 \pm 1.3$ & $t=-3.03$ \\
\hline Female & 129 & $7.1 \pm 1.1$ & $\mathrm{p}=0.003$ \\
\hline
\end{tabular}
attitude, practice scores with gender

reported "involvement in planning or helping to plan the meals in their households", $59.0 \%$ usually/always and $18.0 \%$ rarely or never involved. Most of the students $82.4 \%$ reported that they usually / always "before preparing or handling food, wash hands with soap and warm running water" while $17.6 \%$ selected sometimes/never. Similarly, $88.1 \%$ of respondents reported that "they wash hands with soap and warm running water after working with raw meat or chicken" while $2.5 \%$ selected sometimes/never for respondents $(79.1 \%)$ reported that they usually / always "keep raw meat and chicken away from ready-to-eat foods like raw vegetables", $17.6 \%$ and $3.3 \%$ selected sometimes and rarely/ never respectively (Table 4). By gender females had higher knowledge, attitude and practice mean scores as regards the food safety and the difference was statistically significant $(\mathrm{t}=$ $3.01 \mathrm{p}=0.003-\mathrm{t}=-2.5 \mathrm{p}=0.013-\mathrm{t}=-$ $3.03 \mathrm{p}=0.003$ respectively) (Table 5). Concerning the association between passing score $(\geq 50 \%)$ of food safety knowledge questions and different characteristics of studied medical students, more females $(56.6 \%)$ had passing knowledge score compared to males (43.4\%) with a marginally significant association $(\mathrm{p}=0.05)$. Faculty grade was significantly associated $(\mathrm{p}=0.023)$ with food safety passing score; $55.0 \%$ of $6^{\text {th }}$ year students passed the safety knowledge score compared to only $37.5 \%$ of first year students. On the other hand, age and living with or away from family showed no significant association (Table 6) 
Table 6. Relation of food safety knowledge and characteristics of studied medical students

\begin{tabular}{|c|c|c|c|}
\hline & \multicolumn{2}{|c|}{ Total knowledge score } & \multirow[t]{2}{*}{ Sig } \\
\hline & $\begin{array}{c}\text { Fail } \\
\text { Mean } \pm \text { SD }\end{array}$ & $\begin{array}{c}\text { Passed } \\
\text { Mean } \pm \text { SD }\end{array}$ & \\
\hline \multirow[t]{3}{*}{ Age } & $21.8 \pm 1.7$ & $22.1 \pm 1.7$ & $\begin{array}{c}t=1.5 \\
p=0.14\end{array}$ \\
\hline & Total know & edge score & \multirow[b]{2}{*}{ Sig. } \\
\hline & $\begin{array}{c}\text { Failed } \\
\text { No. }(\%) \\
\end{array}$ & $\begin{array}{c}\text { Passed } \\
\text { No. }(\%) \\
\end{array}$ & \\
\hline \multicolumn{4}{|l|}{ Gender } \\
\hline Male & $79(68.7)$ & $36(31.3)$ & \multirow{2}{*}{$\begin{array}{l}x^{2}=3.8 \\
p=0.05\end{array}$} \\
\hline Female & $73(56.6)$ & $56(43.4)$ & \\
\hline \multicolumn{3}{|l|}{ Grade } & \multirow{7}{*}{$\begin{array}{l}\mathrm{x}^{2}=13.1 \\
\mathrm{p}=0.023\end{array}$} \\
\hline 1.0 & $15(62.5)$ & $9(37.5)$ & \\
\hline 2.0 & $12(57.1)$ & $9(42.9)$ & \\
\hline 3.0 & $25(80.6)$ & $6(19.4)$ & \\
\hline 4.0 & $58(59.8)$ & $39(40.2)$ & \\
\hline 5.0 & $24(77.4)$ & $7(22.6)$ & \\
\hline 6.0 & $18(45.0)$ & $22(55.0)$ & \\
\hline \multicolumn{4}{|l|}{ Residency } \\
\hline $\begin{array}{l}\text { Living } \\
\text { with }\end{array}$ & $80(60.6)$ & $52(39.4)$ & \multirow{3}{*}{$\mathrm{x}^{2}=0.4 \mathrm{p}=0.3$} \\
\hline $\begin{array}{l}\text { family } \\
\text { Living }\end{array}$ & & & \\
\hline $\begin{array}{c}\text { away } \\
\text { from } \\
\text { family }\end{array}$ & $72(64.3)$ & $40(35.7)$ & \\
\hline
\end{tabular}

As regards the relation between grades and knowledge score there was statistical difference showing higher score with higher grades $\mathrm{f}=2.56 \mathrm{p}=0.028$, while there was non-significant difference with attitude, and practice scores (Data not shown).Knowledge score correlation with attitude and practice scores showed no statistical significance $(\mathrm{r}=0.04 \mathrm{p}=0.45$ and $\mathrm{r}=0.11 \mathrm{p}=0.07$ respectively).Correlation between attitude score and practice score showed a statistically significant difference $(\mathrm{r}=0.28 \mathrm{p}=0.000)$ (Table 7).

\section{Discussion}

Although the public is increasingly concerned about food-related risks, the rise in food born disease cases suggests that people still consume, store and prepare food using improper, unhealthy and unsafe ways. ${ }^{13}$ Recent studies have shown that around 50 to $87 \%$ of foodborne outbreaks occur due to wrong home practices. ${ }^{6}$ The current study showed an insufficient level of food safety knowledge among medical students with a mean \pm SD of $2.2 \pm 1.3$. Correct answers for the six food safety knowledge questions were selected by less than $50 \%$ of studied medical students; this agrees with many studies reporting low level of food safety knowledge among young adults and adolescents. ${ }^{15-16}$ In the present study, students were least knowledgeable on the correct duration of keeping leftovers refrigerated as well as the most hygienic way to wash hands. The current study results revealed a statistically significant highest proportion of students scoring $(\geq 50 \%)$ on food safety knowledge score among senior students (Sixth year). This finding is similar to the results of Osaili et al., 2011 carried out among Jordanian college female students as well as another study carried out in Saudi Arabia among school students. ${ }^{11,17}$

Table 7. Correlation between age and studied medical students scores of food safety knowledge, attitude and practice

\begin{tabular}{llrrr}
\hline & & $\begin{array}{c}\text { Attitude } \\
\text { score }\end{array}$ & $\begin{array}{c}\text { Practice } \\
\text { score }\end{array}$ & \multicolumn{1}{c}{ age } \\
\hline Knowledge & $\mathrm{r}_{\mathrm{p}}$ & 0.048 & 0.115 & 0.113 \\
& $\mathrm{P}$ value & 0.458 & 0.073 & 0.078 \\
& $\mathrm{~N}$ & 244 & 244 & 244 \\
\hline Attitude & $\mathrm{r}_{\mathrm{p}}$ & & $0.283^{* *}$ & 0.008 \\
& $\mathrm{P}$ value & -- & 0.000 & 0.895 \\
& $\mathrm{~N}$ & & 244 & 244 \\
\hline Practice & $\mathrm{r}_{\mathrm{p}}$ & & & 0.124 \\
& $\mathrm{P}$ value & -- & -- & 0.053 \\
& $\mathrm{~N}$ & & & 244 \\
\hline
\end{tabular}

In the present study females had significantly higher knowledge, attitude and practice mean scores. Similarly, concerning knowledge about the correct action to be done if they have a sore on their hand $35 \%$ of studied students reported that they "should bandage the sore and wear a glove". Females had better 
knowledge and the difference was statistically significant $(27.8 \%$ among males compared to $41.9 \%$ among females) $\left.\mathrm{x}^{2}=10.3 \mathrm{p}=0.036\right)$. These findings agree with many studies showing that females have significantly higher food safety knowledge, attitude and practice. ${ }^{11,15,16,17}$ The current study findings show that female students are more informed about food safety than male students. This may be due to the fact that females are more interested in food preparation and cooking especially in our country. Similarly, in the present study, senior students were more informed; this is probably because they studied microbiology, public health and internal medicine and these curricula increased significantly their food safety level of knowledge. Knowledge score correlation with attitude and practice scores showed no statistical significance $(\mathrm{r}=0.04 \mathrm{p}=0.45$ and $\mathrm{r}=0.11 \mathrm{p}=0.07$ respectively). This disagrees with Sanlier, 2009 study revealing a significant correlation between food safety knowledge and practice scores. ${ }^{2}$ On the other hand, the current study finding agrees with USDAFSIS, (2002) report, showing that consumers good knowledge level on food safety may not always result in safe food practices. ${ }^{18}$ However, in the present study, a statistically significant positive correlation between attitude score and practice score was shown $(\mathrm{r}=0.28 \mathrm{p}=0.000)$ as students with more positive food safety attitude reported safer food practices.

The findings of the current study highlighted the need to develop continued consumer education on different aspects of food safety (storing, preparation and handling). This education should start from early childhood years. Target population for food safety education are not only food handlers, but all consumers of all age categories especially males, as most of food safety related morbidities are due to domestic unsafe food practices and can be easily prevented.

\section{Limitation of the study}

As the study population consisted of medical students, the results cannot be generalized to all university students or to all ages. In addition, the practice responses were self-reported, which may lead to bias.

\section{References}

1. Linscott, A.J. (2011). Foodborn illness. Clinical Microbiology Newsletter, 33, 41-45.

2. Sanlier, N. (2009). The knowledge and practice of food safety by young and adult consumers. Food Control, 20, 538-542.

3. Byrd-Bredbenner C, Berning J, MartinBiggers J \& Quick V (2013). Food safety in home kitchens: a synthesis of the literature. Int J Environ Res Public Health. 2013 Sep 2;10(9):4060-85. doi: 10.3390/ijerph10094060. PubMed PMID: 24002725; PubMedCentral PMCID: PMC3799528.

4. WHO. (2007). Food safety and foodborne illness. Fact sheet No. 237, available from http://www.who.int/mediacentre/factsheets/fs2 37/en/index.html (Last accessed December 2018) .

5. Lynch M, Painter J, Woodruff R \& Braden C (2006). Centers for Disease Control and Prevention. Surveillance for foodborne-disease outbreaks--United States, 1998-2002. MMWR Surveill Summ. 2006 Nov 10;55(10):1-42. PubMed PMID: 17093388.

6. Redmond EC, Griffith CJ (2003). Consumer food handling in the home: a review of food safety studies. J Food Prot. 2003 Jan;66(1):130-61. Review. PubMed PMID:12540194.

7. Centers for Disease Control and Prevention. Number of Reported Foodborne Disease Outbreaks and Outbreak-Associated Illnesses, by Etiology and Place Where Food Was Eaten-United States, 2008. Available online: http://www.cdc.gov/outbreaknet/pdf/2008M MWR-Table3.pdf. (last accessed December 2018) 
8. Centers for Disease Control and Prevention. Surveillance for Foodborne Disease Outbreaks- United States, 1998-2008. Morbidity and Mortality Weekly Report. Available online: http://www.cdc.gov/mmwr/pdf/ss/ss6202.pd f. (last accessed December 2018)

9. Scott E. (2003). Food safety and foodborne disease in 21 st century homes. The Canadian journal of infectious diseases $=$ Journal canadien des maladies infectieuses, 14(5), 277 80 .

10.Byrd-Bredbenner, C., Wheatley, V., Schaffner, D., Bruhn, C., Blalock, L., \& Maurer, J. (2007). Development of food safety psychosocial questionnaires for young adults. Journal of Food Science Education, 6, 30-37.

11.Tareq M. Osaili, Bayan A. Obeidat, Dima O. Abu Jamous, Hiba A. Bawadi (2011), Food safety knowledge and practices among college female students in north of Jordan, Food Control, Volume 22, Issue 2, 2011, 269-276.

12.Hassan, H.F., Dimassi,H. (2014). Food safety and handling knowledge and practices of Lebanese university students. Food Control 40 (2014) 127-133.

13. Majowicz SE, Diplock KJ, Leatherdale ST, Bredin CT, Rebellato S, Hammond D, JonesBitton A, Dubin JA (2016). Food safety knowledge, attitudes and self-reported practices among Ontario high school students. Can J Public Health. 2016 Mar 16;106(8):e520-6. doi: 10.17269/cjph.106.5213. PubMed PMID: 26986914.

14.McCarthy, M., M. Brennan, A. L. Kelly, C. Ritson, M. de Boer and N. Thompson. (2007) 'Who is at Risk and What do they Know? Segmenting a Population on their Food Safety Knowledge', Food Quality and Preference 18(2): 205-17.

15.Garayoa R, Córdoba M, García-Jalón I, Sanchez-Villegas A, Vitas AI. (2005). Relationship between consumer food safety knowledge and reported behavior among students from health sciences in one region of Spain. J Food Prot. 2005 Dec;68(12):2631-6. PubMed PMID: 16355835.

16.Sharif, L., \& Al-Malki, T. (2010). Knowledge, attitude and practice of Taif University students on food poisoning. Food Control, 21, 55-60.

17. Almansour M, Sami W, Al-Rashedy OS, Alsaab RS, Alfayez AS, Almarri NR. (2016) Knowledge, attitude, and practice (KAP) of food hygiene among schools students'in Majmaah city, Saudi Arabia. J Pak Med Assoc. 2016 Apr;66(4):442-6.

18. USDA-FSIS (2002): Pathogen Reduction: Hazard Analysis and Critical Control Point (PR/ HACCP) Rule and Evaluation Final Report: Changes in Consumer Knowledge, Behavior, and Confidence Since the 1996 PR/HACCP Final Rule. United 